Original Article

\title{
Comparison of therapeutic duration of therapeutic ultrasound in patients with knee osteoarthritis
}

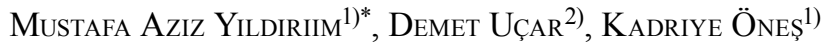 \\ 1) Istanbul Physical Therapy Rehabilitation, Education and Research Hospital: Kocasinan Mah, Ordu \\ Cad, Elitler Apt no 15-17/15 Bahçelievler, Istanbul, Turkey \\ 2) Istanbul Medeniyet University Göztepe Education and Research Hospital, Turkey
}

\begin{abstract}
Purpose] The aim of study was to compare different durations of ultrasound in patients with knee osteoarthritis. [Subjects and Methods] One hundred patients diagnosed with bilateral knee osteoarthritis (OA) were enrolled in this study. Patients were divided into two groups. The first group (G1) received 4 minutes of ultrasound. The second group $(\mathrm{G} 2)$ received the exact same treatment, but the duration of ultrasound was longer at 8 minutes. Patients in both groups underwent a total of 10 ultrasound over 2 weeks. Following treatment, all patients provided self-evaluations of pain via the Visual Analog Scale (VAS), overall physical function with WOMAC, disability via the Lequesne index (Leq), and depressive symptoms with the Beck Depression Index (BDI). [Results] There were no significant differences in VAS, WOMAC Leq, and BDI values between groups 1 and 2. After treatment, VAS, WOMAC, Leq, and BDI values improved for both treatment groups. However, following treatment, G2 had significantly greater values for WOMAC functional and total scores than G1. No statistically significant differences were observed for VAS scores while inactive, WOMAC pain and stiffness scores, and BDI values after treatment between both groups. VAS pain scores while active and Leq index values were significantly lower in G1 than G2. [Conclusion] Patients in both groups demonstrated improved functionality, pain and psychological status following a consistent, 2-week regimen of 4-minute or 8-minute treatments with ultrasound. Yet, patients that experienced longer treatment durations of 8 minutes demonstrated better outcomes in pain and the ability to carry out activities of daily living.

Key words: Knee, Ultrasound, Osteoarthritis
\end{abstract}

(This article was submitted Jul. 8, 2015, and was accepted Sep. 2, 2015)

\section{INTRODUCTION}

Osteoarthritis (OA) is the most common chronic progressive joint disease in the elderly and has a significant impact on quality of life as functional status decreases as a result of the pain. Furthermore, difficulties in carrying out activities of daily living have detrimental effects on psychological well-being. In general, the goals of clinically managing knee $\mathrm{OA}$ are to provide pain relief and to maintain or to improve functionality. A diverse range of pharmacological, non-operative and surgical options are available for treating OA, yet each therapeutic modality has its respective limitations and side effects ${ }^{1)}$. Short-wave diathermy, transcutaneous electrical nerve stimulation, ultrasound (US) therapeutic acoustic radiation, and applying hot packs are all commonly utilized noninvasive modalities to control both acute and chronic OA pain $^{2)}$. Therapeutic acoustic radiation is transmitted into target tissues by US via high-frequency pressure waves that are

\section{*Corresponding author. Mustafa Aziz Yildırım (E-mail: mustafaaziz1907@hotmail.com)}

C2015 The Society of Physical Therapy Science. Published by IPEC Inc. This is an open-access article distributed under the terms of the Creative Commons Attribution Non-Commercial No Derivatives (by-ncnd) License $<$ http://creativecommons.org/licenses/by-nc-nd/3.0/> . generated by piezoelectric crystals in the transducer. Heat is generated by the pressure waves, and it has been shown that low-intensity US pulses stimulate cellular metabolism that enhance tissue regenerative capacity ${ }^{3-6)}$. This relatively new treatment modality has been shown to promote the repair of full-thickness tears in articular cartilage. Specifically, it has been found that the pressure waves induce stromal cell and chondrocyte proliferation in addition to mesenchymal stem cell differentiation at the lesion site ${ }^{7-9}$. However, the therapeutic effects of US are more pronounced in the joint spaces, such as the knee joints, because synovial fluid has high water content ${ }^{10)}$. It is the one of several physical therapy modalities suggested for the management of pain and loss of function due to OA and can be used as part of an over all rehabilitation program ${ }^{11)}$.

Several studies compare US and physical therapy versus placebo for patients with knee OA, but the clinical efficacy of US remains controversial ${ }^{2,12-21)}$. Despite these results, US therapeutic acoustic radiation is still very popular for the treatment of musculoskeletal disorders and it has been asserted that it reduces edema, relieves pain, and increases range of motion ${ }^{12-14)}$. The aim of this prospective randomized single-blinded trial was to evaluate whether an 8-minute regimen of US therapeutic acoustic radiation is superior to a 4-minute regimen for the treatment of knee OA. 


\section{SUBJECTS AND METHODS}

This prospective randomized single-blinded trial was conducted at the Istanbul Physical Medicine and Rehabilitation Training Hospital in Turkey. A total of 100 patients between the ages of 40-70 years diagnosed with knee OA and a Kellgren-Lawrence grade of 2 or 3 according to American College of Rheumatology criteria were enrolled in the study ${ }^{22,23)}$. Exclusion criteria from the study included: any contraindications against performing physical therapy, dermatological problems, any systemic disease, abnormal laboratory test results, previous history of knee surgery or arthroplasty, previously participating in a physical therapy program, previous history of hyaluronic acid or steroid intraarticular injections, or having US therapeutic acoustic radiation within the last 6 months.

Patients were evaluated at baseline and after the entire treatment regimen lasting 2 weeks by a certified physician who was blinded to patient treatment condition. Informed consent was obtained from all subjects after the nature of the study had been fully explained. The study was approved by our institution's ethics committee and was carried out in accordance with the principles of the Declaration of Helsinki. Patients were asked to rate their pain level via a visual analogue scale (VAS) at rest and during activity. Scores ranged from 0 to 10 , with a score of 0 indicating no pain and 10 indicating extremely severe pain ${ }^{22)}$. The Turkish translated version of the Western Ontario and McMaster Universities Osteoarthritis Index (WOMAC) was utilized to assess OA patient symptoms ${ }^{23}$. The 24-item WOMAC is a self-administered questionnaire that is divided into 3 subscales including pain (5 questions, score range: 0-20), joint stiffness (2 questions, score range: $0-8$ ), and physical functionality (17 questions, score range: $0-68)^{24)}$. Previous studies demonstrated that this scale is both a valid and reliable tool to evaluate patients with knee $\mathrm{OA}^{25,26)}$. Higher scores on the WOMAC indicate more severe OA symptoms and so translate to more profound physical limitations. The extent of patient disability was evaluated with the Lequesne (Leq) index ${ }^{27)}$. The questionnaire is comprised of 11 items regarding knee discomfort, ability to endure ambulation, and difficulties in carrying out activities of daily living. A maximum score of 26 indicates the greatest degree of disability. The Beck Depression Inventory (BDI) was utilized to measure the intensity and severity of patient depressive symptoms. Specifically it is composed of 21 questions and a score of 9 and above was considered to be a diagnosis of depression $^{28)}$.

Patients were randomly divided into two groups. The first group (G1) received 4-minute US therapeutic acoustic radiation treatments, performed exercise, and received transcutaneous electrical nerve stimulation. The second group (G2) received an identical treatment, but instead these patients were treated with 8-minute regimens of US therapeutic acoustic radiation. Continuous ultrasonic waves were delivered at a $1 \mathrm{MHz}$ frequency and at an intensity of 1.5 watt/ $\mathrm{cm}^{2}$ via a transducer with a diameter of $5 \mathrm{~cm}$ (Chattanooga, USA). The patient maintained a supine position with both knees fully extended throughout treatment while US therapeutic acoustic radiation was directed around the knee joint.
Table 1. Demographic features

\begin{tabular}{|c|c|c|c|}
\hline & & Group 1 & Group 2 \\
\hline & & Mean \pm SD / n- $\%$ & Mean \pm SD / n- $\%$ \\
\hline \multirow{2}{*}{ Gender } & Female & $2958.0 \%$ & $3774.0 \%$ \\
\hline & Male & $21 \quad 42.0 \%$ & $1326.0 \%$ \\
\hline \multicolumn{2}{|c|}{ Age (years) } & $56.44 \pm 9.346$ & $56.72 \pm 10.306$ \\
\hline \multicolumn{2}{|c|}{ BMI $\left(\mathrm{kg} / \mathrm{m}^{2}\right)$} & $30.24 \pm 4.412$ & $31.01 \pm 4.633$ \\
\hline \multirow{3}{*}{$\begin{array}{l}\text { Marital } \\
\text { status }\end{array}$} & Married & $3774.0 \%$ & $3876.0 \%$ \\
\hline & Single & $0 \quad 0.0 \%$ & $24.0 \%$ \\
\hline & Divorced & $1326.0 \%$ & $1020.0 \%$ \\
\hline \multirow{3}{*}{ Profession } & House wife & $1734.0 \%$ & $1530.0 \%$ \\
\hline & Working & $1428.0 \%$ & $1734.0 \%$ \\
\hline & Retired & $1938.0 \%$ & $18 \quad 36.0 \%$ \\
\hline \multicolumn{2}{|c|}{ Duration (years) } & $4.66 \pm 2.446$ & $4.50 \pm 2.375$ \\
\hline
\end{tabular}

Aqueous gel was utilized as a coupling medium to facilitate the transmission of the high pressure waves. The transducer was moved in a circular fashion at a 90 degree angle to the knee surface during treatment. Every patient received 20 minutes of superficial heating therapy delivered via infrared radiation, 20 minutes of TENS, and 15 minutes of isometric quadriceps exercises for both knees. Patients in each group received treatments five times weekly for a total of 2 weeks. Nonsteroidal anti-inflammatory drugs and antidepressants were not permitted throughout the course of treatment, but medications for the treatment of comorbid diseases were permitted during the study. Data were analyzed using the Statistical Package for Social Sciences (SPSS) version 21.0 for Windows (SPSS Inc., Chicago, IL, USA). Demographic data were presented as the mean plus or minus one standard deviation (SD). Categorical data were analyzed via the $\chi^{2}$ test. The Kolmogorov-Smirnov test was utilized to determine whether continuous variables followed a normal distribution. The Mann-Whitney U-test and independent samples t-test were used to perform quantitative analyses of the data. The Wilcoxon test was used to assess whether sample means differ over repeated measurements. Statistical significance was achieved with p-values less than 0.05 .

\section{RESULTS}

The mean ages of groups 1 and 2 were $56.44 \pm 9.35$ years and $56.72 \pm 10.35$ years, respectively. There were no statistically significant differences between sociodemographic data between each group ( $\mathrm{p}>0.05$; Table 1$)$.

There were no significant differences between baseline VAS, Leq, BDI and WOMAC values between each group $(\mathrm{p}>0.05)$. Following treatment, VAS, WOMAC, Leq, and BDI values decreased for both treatments groups (Tables 2 and 3). G1 demonstrated significantly lower WOMAC functional and total scores (Table 2). No statistically significant differences were observed for VAS at rest values, WOMAC pain and stiffness scores, and BDI values after treatment between G1 and G2 ( $\mathrm{p}>0.05)$.

VAS in activity values and Leq index values were significantly lower in G1 than G2 (Table 3). 
Table 2. Womac values

\begin{tabular}{llcc}
\hline & & Group 1 & Group 2 \\
\hline & & Mean \pm SD / n- $\%$ & Mean \pm SD / n- $\%$ \\
\hline \multirow{2}{*}{ WOMAC } & Before & $11.70 \pm 4.176$ & $11.10 \pm 4.423$ \\
pain & After & $7.54 \pm 3.098$ & $6.62 \pm 3.356$ \\
& Difference & $-4.16 \pm 2.034$ & $-4.48 \pm 1.854$ \\
WOMAC & Before & $1.52 \pm 2.053$ & $2.22 \pm 2.207$ \\
stiffness & After & $0.92 \pm 1.469$ & $1.12 \pm 1.272$ \\
& Difference & $-0.60 \pm 0.728$ & $-1.10 \pm 1.460$ \\
WOMAC & Before & $38.06 \pm 11.134$ & $36.60 \pm 8.760$ \\
function & After & $27.62 \pm 10.851$ & $23.96 \pm 6.755$ \\
& Difference & $-10.44 \pm 4.343$ & $-12.64 \pm 5.244$ \\
\multirow{2}{*}{ WOMAC } & Before & $51.28 \pm 15.115$ & $49.88 \pm 13.055$ \\
total & After & $36.08 \pm 14.045$ & $31.42 \pm 9.712$ \\
& Difference & $-15.20 \pm 5.914$ & $-18.46 \pm 7.083$ \\
\hline
\end{tabular}

Womac: Western Ontario and McMaster Universities Osteoarthritis Index

\section{DISCUSSION}

In this study we investigated the relative effectiveness of US therapeutic acoustic radiation for patients with knee OA over 8-minute and 4-minute treatment sessions. Patients also received physical therapy sessions and transcutaneous electrical nerve stimulation throughout the study and significant improvement was noted in self-ratings of pain intensity, physical functionality, and depressive symptoms. Yet, patients randomly assigned to the 8-minute US group achieved better results in their pain and ability to perform activities of daily living in comparison to patients receiving 4-minute treatments. There are conflicting data regarding the efficacy of US therapeutic acoustic radiation treatment for knee $\mathrm{OA}^{29-34)}$. Specifically, in 2010 the International Osteoarthritis Research Society recommended that the optimal management for hip and knee OA requires a combination of non-pharmacological and pharmacological modalities including physical therapy, but does not specifically mention US therapeutic acoustic radiation as an adjunct ${ }^{35}$. Several authors have researched the effectiveness of US therapeutic acoustic radiation treatment, but its clinical efficacy remains controversial ${ }^{2,15-20)}$. However, our findings indicate that US therapeutic acoustic radiation treatment may be more effective in treating knee OA than previously thought. In fact a study that Ozgonenel et al. ${ }^{16)}$ compared US with sham US in the treatment of knee OA revealed that US was superior to placebo, yet there were further OA treatments provided that may have obscured whether or not the effect was due to US alone.

The intensity, the size of the area treated, and the duration of US therapeutic acoustic radiation treatment used in previously published studies varies considerably and there is little guidance in the literature as to what may be the optimal dosage to treat knee OA.

Yet, it has been recommended that for degenerative arthritis, US should be provided at a constant intensity from 0.5 to 2 watts $/ \mathrm{cm}^{2}$ for 5 to 10 minutes ${ }^{36)}$. Guided by these recommendations, we utilized an intensity of 1.5 watts $/ \mathrm{cm}^{2}$
Table 3. VAS, Leq and BDI values

\begin{tabular}{llcc}
\hline & & Group 1 & Group 2 \\
\hline & & Mean \pm SD / n- $\%$ & Mean \pm SD / n- $\%$ \\
\hline \multirow{3}{*}{ VAS } & Before & $2.58 \pm 2.357$ & $2.28 \pm 2.129$ \\
& After & $1.44 \pm 1.554$ & $1.00 \pm 1.262$ \\
& Difference & $-1.14 \pm 0.948$ & $-1.28 \pm 1.310$ \\
VAS in & Before & $6.96 \pm 1.895$ & $6.70 \pm 1.344$ \\
activity & After & $4.46 \pm 1.775$ & $3.48 \pm 1.389$ \\
& Difference & $-2.50 \pm 1.074$ & $-3.22 \pm 1.130$ \\
& Before & $13.32 \pm 3.689$ & $12.44 \pm 3.715$ \\
Leq & After & $9.50 \pm 3.627$ & $6.98 \pm 3.172$ \\
& Difference & $-3.82 \pm 1.826$ & $-5.46 \pm 2.062$ \\
& Before & $14.38 \pm 9.352$ & $12.72 \pm 8.461$ \\
BDI & After & $11.34 \pm 7.612$ & $9.84 \pm 7.366$ \\
& Difference & $-3.04 \pm 2.020$ & $-2.88 \pm 1.560$ \\
\hline
\end{tabular}

VAS: Visual Analog Scale, Leq: Lequesne index, BDI: Beck Depression Index

over 4 or 8 minutes in our study.

It has been reported that US therapeutic acoustic radiation provides pain relief and improvement in functionality for patients with knee $\mathrm{OA}^{15,16-19)}$. In our study, VAS pain scores improved and WOMAC scores were better after treatment for both treatment groups. Yet, Ulus et al. ${ }^{21)}$ demonstrated no increase in WOMAC functionality scores for patients receiving US treatment versus those receiving sham US treatment.

In Sale et al. ${ }^{37)}$ study, general depression is commonly observed in patients who suffer from chronic pain. Ozcetin et al. $^{38)}$ showed the prevalence of depressive symptoms is high among the elderly with OA. Axford et al. ${ }^{39)}$ has identified an association between depression, disability, pain, and symptom severity in patients with knee OA. In our study, the BDI was used to assess the degree of depressive symptoms and a decrease in depressive symptoms was seen in both treatment groups such that their self-ratings of depression did not differ significantly. Similarly, Ulus et al. ${ }^{21)}$ studied the effects of US therapeutic acoustic radiation on patient psychological well-being and there were no differences between groups after receiving treatment as well.

Huang et al. ${ }^{18)}$ showed that patient perception of impairment and disability due to OA are important factors in patient ratings of disease severity. Deniz et al. ${ }^{40)}$ studied effectiveness of pulsed and continuous diclofenac gel phonophoresis with topical diclofenac gel treatment in knee osteoarthritis. They showed that both continuous and pulsed ultrasound diclofenac gel phonophoresis is more effective for pain and functional status of patients with knee osteoarthritis than topical application of diclofenac gel. Yildırım et al. ${ }^{41)}$ compared the efficacy of ultrasound treatments of 4- and 8minute durations for patients with subacromial impingement syndrome. Eight minutes of ultrasound treatment was shown to be more effective than 4 minutes of ultrasound treatment. In this study, Lequesne disability scores and WOMAC scores decreased significantly in both groups following treatment. Furthermore, the 8-minute treatment group reported a significantly better improvement in physical functionality than the 4-minute treatment group. These results suggest that longer 
US therapeutic acoustic radiation treatment durations may confer greater improvement in patient functionality and ability to perform activities of daily living. In all, our findings indicate that US therapeutic acoustic radiation treatment has true potential in improving symptoms for patients with knee $\mathrm{OA}$. We recommend that further studies are performed in the future to develop a standardized treatment protocol to optimize the therapeutic benefit of this modality for patients with OA.

\section{REFERENCES}

1) Hochberg MC, Altman RD, April KT, et al. American College of Rheumatology: American College of Rheumatology 2012 recommendations for the use of nonpharmacologic and pharmacologic therapies in osteoarthritis of the hand, hip, and knee. Arthritis Care Res (Hoboken), 2012, 64: 465-474. [Medline] [CrossRef]

2) Cetin N, Aytar A, Atalay A, et al.: Comparing hot pack, short-wave diathermy, ultrasound, and TENS on isokinetic strength, pain, and functiona status of women with osteoarthritic knees: a single-blind, randomized, controlled trial. Am J Phys Med Rehabil, 2008, 87: 443-451. [Medline] [CrossRef]

3) Kristiansen TK, Ryaby JP, McCabe J, et al.: Accelerated healing of dista radial fractures with the use of specific, low-intensity ultrasound. A multicenter, prospective, randomized, double-blind, placebo-controlled study. J Bone Joint Surg Am, 1997, 79: 961-973. [Medline]

4) Rubin C, Bolander M, Ryaby JP, et al.: The use of low-intensity ultrasound to accelerate the healing of fractures. J Bone Joint Surg Am, 2001, 83-A: 259-270. [Medline]

5) Rodríguez M: Electroterapia en Fisioterapia. 2nd ed. España: Médica Panamericana, 2004.

6) Hüter-Becker A: Terapia física. Barcelona: Ed. Paidotribo, 2005, pp 211219.

7) Yang PF, Li D, Zhang SM, et al.: Efficacy of ultrasound in the treatment of osteoarthritis of the knee. Orthop Surg, 2011, 3: 181-187. [Medline] [CrossRef]

8) Malone A, Narain R, Jacobs C: Biomechanical regulation of mesenchyma stem and progenitor cells and the implications for regenerative medicine. Curr Op in Ortho, 2005, 363-367. [CrossRef]

9) Loyola Sánchez A, Ramirez Wakamatzu MA, Vazquez Zamudio J, et al.: [Effect of low-intensity pulsed ultrasound on regeneration of joint cartilage in patients with second and third degree osteoarthritis of the knee] Reumatol Clin, 2009, 5: 163-167. [Medline]

10) Weishaupt D, Schweitzer ME, Rawool NM, et al.: Indirect MR arthrography of the knee: effects of low-intensity ultrasound on the diffusion rate of intravenously administered Gd-DTPA in healthy volunteers. Invest Radiol, 2001, 36: 493-499. [Medline] [CrossRef]

11) Rand SE, Goerlich $C$, Marchand $K$, et al.: The physical therapy prescription. Am Fam Physician, 2007, 76: 1661-1666. [Medline]

12) Morishita K, Karasuno H, Yokoi $Y$, et al.: Effects of therapeutic ultrasound on range of motion and stretch pain. J Phys Ther Sci, 2014, 26: 711-715. [Medline] [CrossRef]

13) Ohwatashi A, Ikeda S, Harada K, et al.: Temperature changes caused by the difference in the distance between the ultrasound transducer and bone during $1 \mathrm{mhz}$ and $3 \mathrm{mhz}$ continuous ultrasound: a phantom study. J Phys Ther Sci, 2015, 27: 205-208. [Medline] [CrossRef]

14) van der Windt DA, van der Heijden GJ, van den Berg SG, et al.: Ultrasound therapy for musculoskeletal disorders: a systematic review. Pain, 1999, 81: 257-271. [Medline] [CrossRef]

15) Tascioglu F, Kuzgun S, Armagan O, et al.: Short-term effectiveness of ultrasound therapy in knee osteoarthritis. J Int Med Res, 2010, 38: 1233 1242. [Medline] [CrossRef]

16) Ozgönenel L, Aytekin E, Durmuşoglu G: A double-blind trial of clinical effects of therapeutic ultrasound in knee osteoarthritis. Ultrasound Med Biol, 2009, 35: 44-49. [Medline] [CrossRef]

17) Eyigör S, Karapolat H, Ibisoğlu U, et al.: [Does transcutaneous electrical nerve stimulation or therapeutic ultrasound increase the effectiveness of exercise for knee osteoarthritis: a randomized controlled study]. Agri, 2008, 20: 32-40. [Medline]

18) Huang MH, Lin YS, Lee CL, et al.: Use of ultrasound to increase effectiveness of isokinetic exercise for knee osteoarthritis. Arch Phys Med Rehabil, 2005, 86: 1545-1551. [Medline] [CrossRef]

19) Kozanoglu E, Basaran S, Guzel R, et al.: Short term efficacy of ibuprofen phonophoresis versus continuous ultrasound therapy in knee osteoarthritis. Swiss Med Wkly, 2003, 133: 333-338. [Medline]

20) Falconer J, Hayes KW, Chang RW: Effect of ultrasound on mobility in osteoarthritis of the knee. A randomized clinical trial. Arthritis Care Res, 1992, 5: 29-35. [Medline] [CrossRef]

21) Ulus Y, Tander B, Akyol Y, et al.: Therapeutic ultrasound versus sham ultrasound for the management of patients with knee osteoarthritis: a randomized double-blind controlled clinical study. Int J Rheum Dis, 2012, 15: 197-206. [Medline] [CrossRef]

22) Carlsson AM: Assessment of chronic pain. I. Aspects of the reliability and validity of the visual analogue scale. Pain, 1983, 16: 87-101. [Medline] [CrossRef]

23) Tüzün EH, Eker L, Aytar A, et al.: Acceptability, reliability, validity and responsiveness of the Turkish version of WOMAC osteoarthritis index. Osteoarthritis Cartilage, 2005, 13: 28-33. [Medline] [CrossRef]

24) Bellamy N, Buchanan WW, Goldsmith $\mathrm{CH}$, et al.: Validation study of WOMAC: a health status instrument for measuring clinically important patient relevant outcomes to antirheumatic drug therapy in patients with osteoarthritis of the hip or knee. J Rheumatol, 1988, 15: 1833-1840. [Medline]

25) Rejeski WJ, Ettinger WH Jr, Shumaker S, et al.: The evaluation of pain in patients with knee osteoarthritis: the knee pain scale. J Rheumatol, 1995 , 22: 1124-1129. [Medline]

26) Roos EM, Klässbo M, Lohmander LS: WOMAC osteoarthritis index. Reliability, validity, and responsiveness in patients with arthroscopically assessed osteoarthritis. Western Ontario and MacMaster Universities. Scand J Rheumatol, 1999, 28: 210-215. [Medline] [CrossRef]

27) Lequesne M: Clinical features diagnostic criteria, functional assessments and radiological classifications of osteoarthritis. Baillieres Clin Rheumatol, 1982, -.: 1-10.

28) Beck AT, Ward CH, Mendelson M, et al.: An inventory for measuring depression. Arch Gen Psychiatry, 1961, 4: 561-571. [Medline] [CrossRef]

29) The Royal Australian College of General Practitioners: Guideline for the non-surgical management of hip and knee osteoarthritis, http://www.racgp.org.au/guidelines/osteoarthritis (Accessed Jul. 23, 2009).

30) Vogels E, Hendricks H, van Baar M: Clinical practice guidelines for physical therapy inpatients with osteoarthritis of the hip or knee. http://www. cebp.n1/media/m11.pdf (Accessed Jun. 9, 2006).

31) Zhang W, Moskowitz RW, Nuki G, et al.: OARSI recommendations for the management of hip and knee osteoarthritis, Part II: OARSI evidencebased, expert consensus guidelines. Osteoarthritis Cartilage, 2008, 16: 137-162. [Medline] [CrossRef]

32) Loyola-Sánchez A, Richardson J, MacIntyre NJ: Efficacy of ultrasound therapy for the management of knee osteoarthritis: a systematic review with meta-analysis. Osteoarthritis Cartilage, 2010, 18: 1117-1126. [Medline] [CrossRef]

33) Rutjes AW, Nüesch E, Sterchi R, et al.: Therapeutic ultrasound for osteoarthritis of the knee or hip. Cochrane Database Syst Rev, 2010, 1: CD003132. [Medline]

34) Wang SY, Olson-Kellogg B, Shamliyan TA, et al.: Physical therapy interventions for knee pain secondary to osteoarthritis: a systematic review. Ann Intern Med, 2012, 157: 632-644. [Medline] [CrossRef]

35) Zhang W, Nuki G, Moskowitz RW, et al.: OARSI recommendations for the management of hip and knee osteoarthritis: part III: changes in evidence following systematic cumulative update of research published through January 2009. Osteoarthritis Cartilage, 2010, 18: 476-499. [Medline] [CrossRef]

36) Basford JR: Physical agents. In: DeLisa JA, Gans BM (eds) Rehabilitation Medicine Principles and Practise. JB Lippincott Co, Philadelphia, 1988, pp 404-424.

37) Sale JE, Gignac M, Hawker G: The relationship between disease symptoms, life events, coping and treatment, and depression among older adults with osteoarthritis. J Rheumatol, 2008, 35: 335-342. [Medline]

38) Ozcetin A, Ataoglu S, Kocer E, et al.: Effects of depression and anxiety on quality of life of patients with rheumatoid arthritis, knee osteoarthritis and fibromyalgia syndrome. West Indian Med J, 2007, 56: 122-129. [Medline] [CrossRef]

39) Axford J, Heron C, Ross F, et al.: Management of knee osteoarthritis in primary care: pain and depression are major obstacles. 2008, 64: 461-467.

40) Deniz S, Topuz O, Atalay N, et al.: Comparison of the effectiveness of pulsed and continuous diclofenac phonophoresis in treatment of knee osteoarthritis. J Phys Ther Sci, 2009, 21: 331-336. [CrossRef]

41) Yildirim MA, Ones K, Celik EC: Comparision of ultrasound therapy of various durations in the treatment of subacromial impingement syndrome. J Phys Ther Sci, 2013, 25: 1151-1154. [Medline] [CrossRef] 